\title{
Short-term expansion of breast circulating cancer cells predicts response to anti-cancer therapy
}

\author{
Bee Luan Khoo ${ }^{1, *}$, Soo Chin Lee ${ }^{2,3, *}$, Prashant Kumar ${ }^{4, *}$, Tuan Zea Tan ${ }^{3}$, Majid

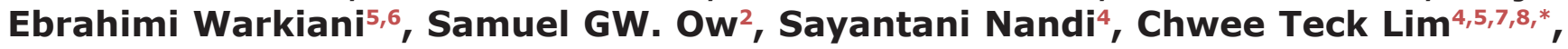 \\ Jean Paul Thiery ${ }^{3,4,9, *}$ \\ ${ }^{1}$ Mechanobiology Institute, National University of Singapore, Singapore \\ ${ }^{2}$ Department of Hematology-Oncology, National University Cancer Institute, National University Hospital, Singapore \\ ${ }^{3}$ Cancer Science Institute of Singapore, National University of Singapore, Singapore \\ ${ }^{4}$ Institute of Molecular and Cell Biology, A*STAR (Agency for Science, Technology and Research), Singapore \\ ${ }^{5}$ BioSystems and Micromechanics (BioSyM) IRG, Singapore-MIT Alliance for Research and Technology (SMART) Centre, \\ Singapore \\ ${ }^{6}$ School of Mechanical and Manufacturing Engineering, University of New South Wales, Sydney, Australia \\ ${ }^{7}$ Department of Biomedical Engineering, National University of Singapore, Singapore \\ ${ }^{8}$ Department of Mechanical Engineering, National University of Singapore, Singapore \\ ${ }^{9}$ Department of Biochemistry Yong Loo Lin School of Medicine, National University of Singapore, Singapore \\ *These authors have contributed equally to this work
}

Correspondence to:

Jean Paul Thiery, e-mail: bchtjp@nus.edu.sg

Keywords: breast cancer, circulating tumor cells, CTCS, enrichment

Received: February 16, $2015 \quad$ Accepted: April 24, $2015 \quad$ Published: May 06, 2015

\section{ABSTRACT}

Circulating tumor cells (CTCs) are considered as surrogate markers for prognosticating and evaluating patient treatment responses. Here, 226 blood samples from 92 patients with breast cancer, including patients with newly diagnosed or metastatic refractory cancer, and 16 blood samples from healthy subjects were cultured in laser-ablated microwells. Clusters containing an increasing number of cytokeratin-positive $(\mathrm{CK}+)$ cells appeared after 2 weeks, while most blood cells disappeared with time. Cultures were heterogeneous and exhibited two distinct subpopulations of cells: 'Small' ( $\leq 25 \mu \mathrm{m}$; high nuclear/cytoplasmic ratio; CD45-) cells, comprising CTCs, and 'Large' (> $25 \mu \mathrm{m}$; low nuclear/cytoplasmic ratio; CD68+ or CD56+) cells, corresponding to macrophage and natural killer-like cells. The Small cell fraction also showed copy number increases in six target genes (FGFR1, Myc, CCND1, HER2, TOP2A and ZNF217) associated with breast cancer. These expanded CTCs exhibited different proportions of epithelial-mesenchymal phenotypes and were transferable for further expansion as spheroids in serum-free suspension or 3D cultures. Cluster formation was affected by the presence and duration of systemic therapy, and its persistence may reflect therapeutic resistance. This novel and advanced method estimates CTC clonal heterogeneity and can predict, within a relatively short time frame, patient responses to therapy.

\section{INTRODUCTION}

Circulating tumor cells (CTCs), derived from either primary or metastatic tumors, have raised considerable interest within the translational oncology community $[1,2]$. CTCs appear during the early stages of tumor progression $[3,4]$ as single cells or cell clusters and exhibit a partial or complete epithelial-mesenchymal transitioned ('EMTed') phenotype [5,6]. These cells may later colonize distant organs and develop into clinically detectable metastases. Thus, studies have proposed that CTCs could be used to provide an assessment of 
the current tumor status via "liquid biopsy" [7-9] or may serve as surrogate markers for patient responses to treatment $[2,10]$ and offer some guidance as to the choice of therapeutic intervention.

Nonetheless, CTCs are rare events, and must be enriched prior to genomic and proteomic analyses. Conventional assays detect only low numbers of CTCs and this poses a significant challenge for defining their characteristics $[10,11]$, particularly since they do not express a targetable marker. Consequently, there is an urgent need for techniques that can successfully expand CTCs. Recent studies have reported the establishment of cell lines derived from CTCs of breast $[12,13]$, colon [14] and prostate [15] cancer patients, obtained following pre-enrichment with affinity binding [12], fluorescenceactivated cell sorting (FACS) [13], or negative selection [15]. However, the efficiencies in obtaining CTC cultures using these methods were low $(<20 \%)$, and the need for pre-enrichment with each method resulted in a loss of CTC count. Hence, there is still a need for a method with improved efficiency and without the need for prior enrichment for practical use in the clinic.

Non-adhesive substrates are typically recommended for culturing cancer stem-like cells from primary tumors, and these cultures tend to generate multilayered cell clusters [16, 17]. Cluster formation can also be promoted using microwells, as described elsewhere for embryonic stem cells $[18,19]$ or cancer cell lines [20]. In addition, it has been indicated that hypoxic conditions $\left(1 \% \mathrm{O}_{2}\right)$ can promote cellular reprogramming towards a cancer stem cell (CSC) phenotype [21, 22]. In consideration of these previous results, we designed and explored the potential clinical utility of a novel culture scheme using laser-ablated microwells that permits the expansion of CTCs from the whole blood of patients with early stage, locally advanced, or metastatic breast cancers. We show that, within the nucleated blood cell fraction, most blood cells (leukocytes, mesenchymal stem cells [23]) and endothelial cells are progressively eliminated from the culture over time, allowing for the selective enrichment of CTCs, which go on to form proliferative clusters. We also demonstrate that these cultured cells comprise two distinct sub-populations: the smaller-sized $(\leq 25 \mu \mathrm{m})$, CD45-negative CTC fraction, with a high nuclear/cytoplasmic $(\mathrm{N} / \mathrm{C})$ ratio, and the larger $(>25$ $\mu \mathrm{m})$ CD68-positive monocytes/macrophages or CD56positive natural killer [24]-like cells, with a low N/C ratio. In further assessment of the Small cell fraction, we show that these cells express either or both epithelial and mesenchymal markers as well as copy number increases in six genes previously identified to be altered in breast cancers. Furthermore, cluster formation in cultures is significantly reduced with samples obtained from patients who had undergone at least one treatment cycle as compared with those samples from untreated patients. Therefore, we surmise that cluster formation may provide a unique and predictive method for treatment response and efficacy.

\section{RESULTS}

\section{CTC culture, characterization and cluster formation}

A laser-ablated, microwell-based assay (Figure 1A1D) for CTC culture was established with nucleated cells from patient blood samples (Supplementary Tables 1A-D) after red blood cell (RBC) lysis (Figure 1D). We sought to culture these cells for up to 14 days. At Day 8, most cultures appeared as a monolayer of cells (Figure 1F, left). By Day 14, the proliferative cultures proceeded to form multilayered clusters, whereas the non-proliferative cultures generated a noticeable amount of cell debris (Figure 1F, right bottom). The clusters formed in the proliferative cultures varied in diameter (Supplementary Figure 2B) and predominantly consisted of a heterogeneous collection of non-senescent cells ( $\sim 90.1 \%$ of $\beta$-galactosidase-negative cells; Supplementary Figure 3).

CTCs immunocaptured by EpCAM antibodies in devices [25, 26], including the FDA-approved CellSearch [27], are often identified as cytokeratin (CK)-positive, CD45-negative cells exhibiting a high $\mathrm{N} / \mathrm{C}$ ratio. We therefore estimated the proportion of CTCs in our cultures in a similar manner, using immunostaining for $\mathrm{CK}$ and CD45 concomitant with a nuclear stain (Hoechst), and using N/C ratio determination. Day 14 proliferative cultures were harvested and analyzed, as summarized in the flow chart in Supplementary Figure 1. Cells were separated into two populations based on size using a spiral inertia microfluidic device [28]. The resultant subpopulations, hereafter referred to as 'Small' $(\leq 25 \mu \mathrm{m})$ and 'Large' ( $>$ $25 \mu \mathrm{m}$ ) cells, were morphologically differentiated using Papanicolaou [29] and Diff-QUIK staining (Supplementary Figure 2A). The Large cells were well differentiated and had a low N/C ratio, whereas the Small cells exhibited strongly stained nuclei and a high $\mathrm{N} / \mathrm{C}$ ratio, features of a malignant phenotype. These cultures also showed variable $\mathrm{CK}$ expression, with $\mathrm{CK}+$ cells localized in the center of the well, surrounded by CD45+ cells (Supplementary Figure 4A). A significant number of these $\mathrm{CK}+$ cells also expressed vimentin (Supplementary Figure 4B), suggesting a transition of these cells from an epithelial to an intermediate EMT phenotype. Most of the large cells within and outside the microwells expressed CD68, which is suggestive of macrophages (Supplementary Figure 4C; Supplementary Methods). The macrophage-like behavior of these cells was confirmed with $1-\mu$ m fluorescein-labeled polystyrene microbeads that were phagocytosed within a 24-h time frame (Supplementary Figure 4D). Outside the microwells, we detected some detached cell clumps, consisting of small cells only, and these cells were negative for CD68 (Supplementary Figure 4C). 

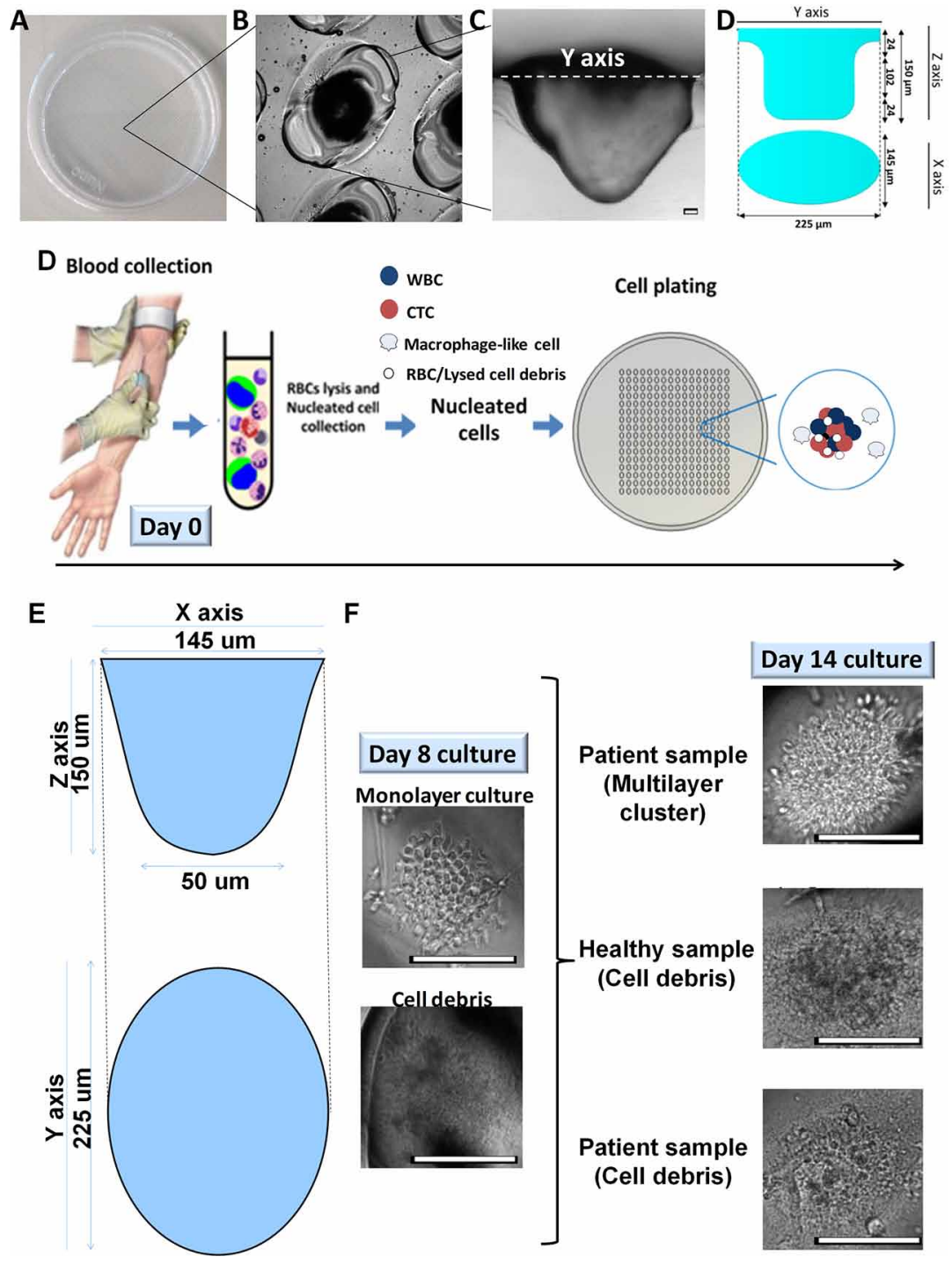

$\mathbf{F}$

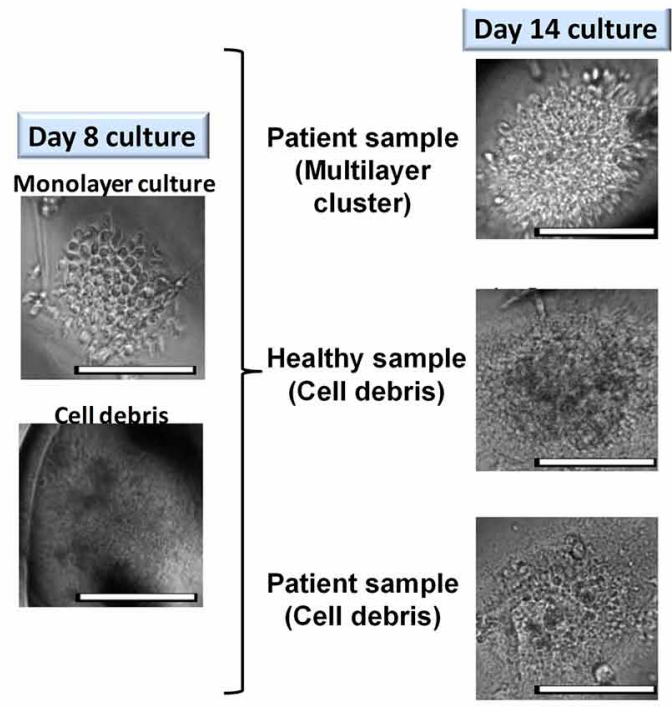

Figure 1: Overview of microwell-based culture technique for CTC expansion. A. Microwell assay is represented by an image of an actual patterned dish with laser-ablated microwells B. Close-up of the microwells at $20 \times$ magnification. C. Cross-section of a polydimethylsiloxane (PDMS) replica for one of the microwells. Scale bar, $10 \mu \mathrm{m}$. D. Preparation of the nucleated cell fraction from peripheral blood via red blood cell (RBC) lysis. E. A schematic diagram displaying estimated dimensions of a microwell. The ellipsoidal tapered microwell has major and minor diameters of $225 \mu \mathrm{m}$ and $145 \mu \mathrm{m}$, respectively, at the opening of the well, and a depth of $150 \mu \mathrm{m}$. F. At Day 8, cultures may appear as a monolayer of cells within microwells, while some of the non-proliferative cultures may have already generated cell debris. Proliferative cultures (top right, patient sample) proceed to form multilayered clusters by Day 14, whereas nonproliferative cultures (second and bottom right, healthy and patient samples) generate cell debris. Scale bar, $100 \mu \mathrm{m}$.

We next sought to compare the proportions of $\mathrm{CK}+/$ CD45- Small cells in cultures at Days 0 (nucleated fraction), 8, 14 and 21 (Figure 2A; Supplementary Figure 5) using cytospot preparations of the cultures; the MDA-MB-231 cell line was used as a negative control. We found that the Small CK + CTC counts increased over time with respect to total cell counts (Figure 2B), and that these increases correlated with the initial abundance of CK+ CTCs in the blood before culture; albeit, some blood samples that did not initially contain detectable $\mathrm{CK}+\mathrm{CTCs}$ were later positive at Day 14 (Supplementary Table 2). The proportion of $\mathrm{CK}+/$ CD45- cells decreased significantly after Day 14 for most samples (Figure 2B, Supplementary Figure 5); therefore, we selected Day 14 as the end-point for culture phenotyping. This time-point also correlated with the highest number of Ki67-positive clusters (Supplementary Figure 6).

Interestingly, we noted that the proportion of CTCs relative to the total cell count varied across the samples examined $(n=10)$, ranging from $37.5 \%$ to $94.6 \%$ (Figure 2B). Non-proliferative blood cells present in the Day 0 nucleated fraction resulted in cell debris that was progressively eliminated with media changes. Macrophages $(\sim 33 \% \pm 26 \%)$ and NK cells $(\sim 22.2 \% \pm 9 \%)$ were identified using leukocyte markers (CD45 and CD18; Figure 2C), a NK 

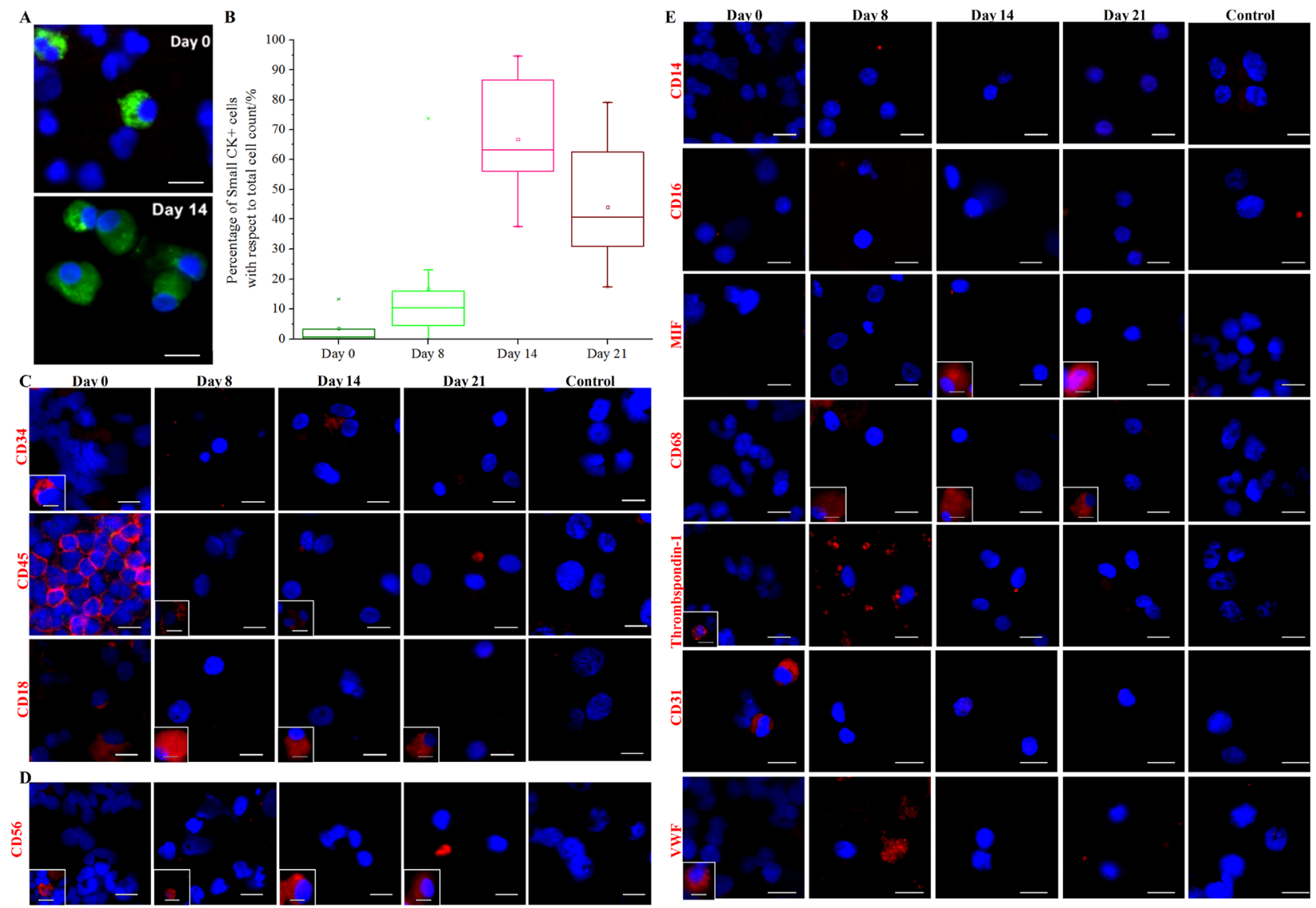

Figure 2: Expansion of CK+ cells and depletion of blood cells in culture. A. Immunostaining (pan-CK-FITC, Hoechst) of cytospots obtained from culturing blood samples harvested at different time points (Days 0, 8, 14 and 21). Scale bar, $20 \mu \mathrm{m}$. B. Percentage of Small CK + cells $(15-25 \mu \mathrm{m})$ with respect to total cell count (Hoechst + ) at various time points (Days $0,8,14$ and 21). Significant expansion of CK + cells can be observed by Day 14. C. Immunostaining of hematopoietic precursors and leukocytes. Boxed images (marked in white) provide examples of a distinct minority phenotype from the majority of cells. CD34+ cells (hematopoietic precursors) disappeared from culture with time. A minority of CD45+ and CD18+ cells persist in culture. Negative control (MDA-MB-231 cell line) for each antibody is provided (last column). Scale bar, $20 \mu \mathrm{m}$. D. Immunostaining for the natural killer cell marker, CD56. Minority populations of CD56+ $(\sim 22.2 \% \pm 9 \%)$ persist in culture. Boxed images (marked in white) provide examples of a distinct minority phenotype from the majority of cells. Negative control (MDA-MB-231 cell line) (to determine antibody specificity) is provided in the last column. Scale bar, $20 \mu \mathrm{m}$. E. Immunostaining of specific white blood cell (WBC) and endothelial cell markers. Boxed images (marked in white) provide examples of a distinct minority phenotype from the majority of cells. Cultured cells are generally negative for thrombospondin-1, CD14, CD16, von Willebrand factor (VWF) and CD31. Minority populations of CD68+ and MIF+ (migration inhibitory factor) cells $(\sim 33 \% \pm 26 \%)$ persist in culture. Negative control (MDA-MB-231 cell line) for each antibody is provided (last column). Scale bar, $20 \mu \mathrm{m}$.

cell marker (CD56; Figure 2D), and macrophage markers (migration inhibitory factor, MIF, and CD68; Figure 2E). Blood cells of other lineages were rarely noted, as revealed by immunostaining for hematopoietic precursors (CD34; Figure 2C), monocytes (CD14 and CD16), megakaryocytes (thrombospondin-1) and endothelial cells (CD31 and von Willebrand factor; Figure 2D). Cells expressing mesenchymal stem cell (MSC)-associated markers were also rarely detected, as determined using antibodies against CD90 and various markers of differentiation (aggrecan for chondrocytes, FABP4 for adipocytes, osteocalcin for osteocytes, and troponin $\mathrm{T}$ for cardiomyocytes; Supplementary Figure 7). Overall, the data demonstrate that cultured cells from cancer patients consisted predominantly of CK+/CD45- CTCs, macrophages, and NK cells.
Finally, we compared these cultures with those of blood samples taken from 16 healthy subjects (Supplementary Table 3). Blood samples from healthy subjects generated monolayers with cell debris (Figure 1E, Supplementary Figure 8A). The cells from the monolayer were $\mathrm{CK}+/$ Hoechst + /CD68+, confirming that they were macrophages (Supplementary Figure 8B).

\section{Enrichment of phenotypes with cancer stem cell (CSC) markers}

Tumor-initiating cells have been shown to carry stem cell-like properties [17,30], as well as drug resistance $[31,32]$ and drug tolerance [33-35]. Breast cancer stem cells (CSCs), initially identified as CD44+/CD24- cells 
[17], are also known to express EMT markers [17, 36]. In several other studies, these CSCs have been detected as a subpopulation in CTC cultures [37-40]. Thus, we next sought to evaluate the presence of CD44+/CD24cells in our culture, and determined the impact of hypoxia and a microwell-based culture system on the expansion of these putative CSCs. Cultures were maintained in one of three conditions, each performed in triplicate: hypoxia (10\% serum, $1 \%$ oxygen) in microwells, hypoxia on 2D-uncoated substrates, or normoxia in microwells. Blood cells were present in all three conditions (Supplementary Figure 9A), but clusters only formed in the hypoxia/ microwell condition after one week in culture. The proportion of CD44+/CD24- cells was lower on the 2D-uncoated substrates or under normoxic conditions, as compared with cultures maintained in microwells under hypoxic conditions (Supplementary Figure 9B). The estimated ratio of CD44+/CD24- cells was 1:0.62:0.42 (hypoxia/microwell: hypoxia/2D substrate: normoxia/ microwell; Supplementary Figure 10). Day 14 cultures under hypoxia/microwell conditions were also positive for Rex1, an embryonic stem cell (ESC) marker (78.5\% $\pm 17 \%$; Supplementary Figure 11), but negative for other ESC markers, SOX2, Oct4 and Nanog. We also found subpopulations of cells with stem cell-like properties, as supported by spheroid formation in 3D Geltrex ${ }^{\circledR}$ or on ultra-low adhesive dishes at Day 14 (Supplementary Figure 12); this suggested the existence of tumorigenic cells. CD44+/CD24- cells were distinctly absent from cultures obtained from these healthy samples (Supplementary Figure 8C).

\section{Cultured CTCs are heterogeneous and contain mesenchymal-associated genes}

We next characterized the expression of epithelial and mesenchymal markers in the Small cell population using six epithelial markers (E-cadherin, CK5, CK7, CK18, CK19 and EpCAM) and two mesenchymal markers (Vimentin and Fascin) (Supplementary Table 4). MCF-7 and MDA-MB-231 cell lines were used as references for epithelial and mesenchymal carcinomas, respectively. Individual $\mathrm{CK}$ immunolabelling demonstrated that cultured cells express higher levels of CK5 and CK7 as compared with CK18 and CK19. Furthermore, cultured cells became increasingly more mesenchymal-like with time in culture, with increased Vimentin and Fascin staining and reduced or absent staining of epithelial markers (E-cadherin and EpCAM; Figure 3). The EMT status of CTCs at Day 14 was heterogeneous, with the majority of cells staining positively for both pan-CK and Vimentin antibodies ( $>50 \%)$.

To better estimate the epithelial-like and mesenchymal-like sub-populations in these cultured CTCs, we used RNA FISH on 10 samples and assessed the expression of nine epithelial genes (CK7, CK8, CK18,
CK19, CDH1, TFF1, FOXA1, AGR2 and GATA3) and four mesenchymal genes (PTX3, SERPINE2, VIM, FASCIN) (Supplementary Table 5, Supplementary Figure 13; Supplementary Methods). Cells were classified as Epithelial (E; mostly green fluorescence), EpithelialMesenchymal (EM; mixed fluorescence) or Mesenchymal (M; mostly red fluorescence), and MCF-7 and MDAMB-231 cells were again used as phenotypic controls. The results showed that the phenotypes of Day 14 samples were indeed mixed, and this was irrespective of their estrogen receptor (ER), progesterone receptor $(\mathrm{PR})$ or HER2 statuses.

\section{Copy number increase in breast cancer-associated genes}

Six genes have been reported to contribute to about $44 \%$ of driver mutations in breast cancer (copy number increase or amplicons): MYC, FGFR1 (Chromosome 8); CCND1 (Chromosome 11); HER2, TOP2A (Chromosome 17); and ZNF217 (Chromosome 20) [24, 41]. We next employed DNA FISH to evaluate the amplification status of these six genes in Day 14 cultured cell samples (Supplementary Table 5; Supplementary Methods). First, we used single probes to ascertain the cells with copy number increase for each of the six genes (Figure 4A), with an increase defined as those cells with three or more red signals. In the 10 samples tested, all (10/10, 100\%) showed a gain in at least one investigated gene locus. However, only $6 / 10$ samples $(60 \%)$ showed $40 \%$ or more cells with copy number increases in 1 or more genes (Figure 4B).

Next, we compared the total proportion of cells with a copy number increase in any of these probes with a concomitant increase in CEN17 copy number (an indicator of cell polyploidy and cancer progression). This was performed using another 27 samples, with all six probes used for each sample (Figure 4C). For this assay, the threshold for signals was increased to $\geq 13$ red signals to indicate copy number increases in the target probe(s); cells with $\geq 3$ green signals were considered to have copy number increase in CEN17. We found that cultured cells with single or multiple CEN17 signals had a copy number increase in one or more target probes, with 21/27 (77.8\%) samples showing a proportion of cells with target gene copy number increase (range, $7.1 \%-80 \%$; mean, 35.9\%) and $25 / 27(92.6 \%)$ samples showing a proportion of cells with a copy number increase in CEN17 (range, 10.3\%$85.7 \%$; mean, 46.2\%; Figure 4D). There was no distinct correlation between CEN17 polysomy and target gene amplification in cultured CTCs, which is similar to that reported in other studies [42]. Overall, the detection of copy number increases in cancer-associated genes within the Small cultured cell population confirms the presence of cancer cells, and we surmise that these Small cells were likely derived from CTCs. 


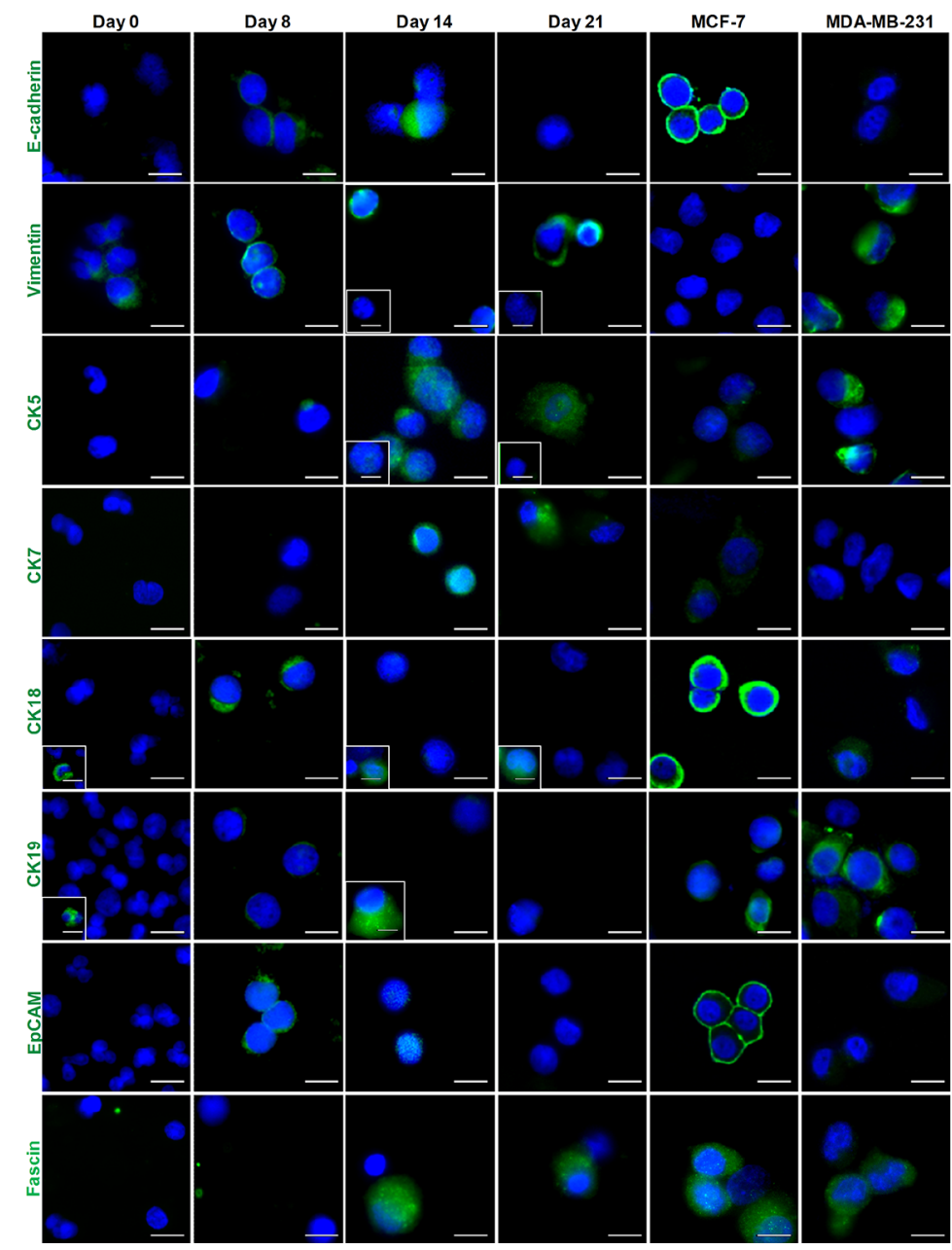

Figure 3: Immunostaining of epithelial and mesenchymal markers for Day 14 cultures. Boxed images (marked in white) provide examples of a distinct minority phenotype from the majority of cells. Cells generally demonstrated increased expression of mesenchymal markers (Vimentin and Fascin), and decreased expression of epithelial markers (EpCAM and E-cadherin). Individual cytokeratin staining (CK5, CK7, CK18 and CK19) demonstrates that the cultured cells are more positive for CK5 and CK7 than CK18 and CK19. MCF-7 and MDA-MB-231 breast cancer cell lines were used as references for epithelial and mesenchymal carcinoma cell lines, respectively. Scale bar, $20 \mu \mathrm{m}$.

\section{Cultures predict response to anti-cancer therapy}

Given that CTCs are considered to be surrogate markers for prognosticating and evaluating patient treatment responses, we next sought to determine the utility of the CTC cluster formation assay as a predictor of treatment response. To this end, we analyzed 173 preand/or post-treatment blood samples from 60 patients with early stage or metastatic breast cancer, who were receiving anti-cancer therapy and who had clinically measurable tumors. These patients had been enrolled into one of three clinical studies - two neoadjuvant trials (Cohort P2A/2B, Cohort PCL) and one metastatic study (Cohort CTB) (Supplementary Tables 1A-1D) - and blood samples were taken from each patient before treatment and at various time points during their treatment course and used for analysis. All patients gave their informed consent. Overall, we found that cluster formation (Figure 1) was seen progressively less frequently in blood samples from patients who had undergone longer durations of systemic therapy (pre-treatment: $39 / 44(88.6 \%) ;<3$ weeks posttreatment: $27 / 32(84.4 \%) ; 3-5$ weeks post-treatment: $24 / 36(66.7 \%)>5$ weeks post-treatment: $26 / 61(42.6 \%)$, $p<0.001)$.

We thus next aimed to link clinicopathological factors with cluster formation in these cultures. Of the $5 / 44(11.3 \%)$ pre-treatment samples that did not form clusters, two were from patients with invasive lobular carcinoma (ILC). Of the $5 / 32(15.6 \%)<3$ weeks posttreatment samples that did not form clusters, one was from a patient with ILC whose baseline sample did not form clusters, whereas another was from a patient who went on to achieve pathological complete response after 12 weeks of neoadjuvant chemotherapy. These findings suggest the potential for cultured CTCs to be used as an early predictor of treatment response. 

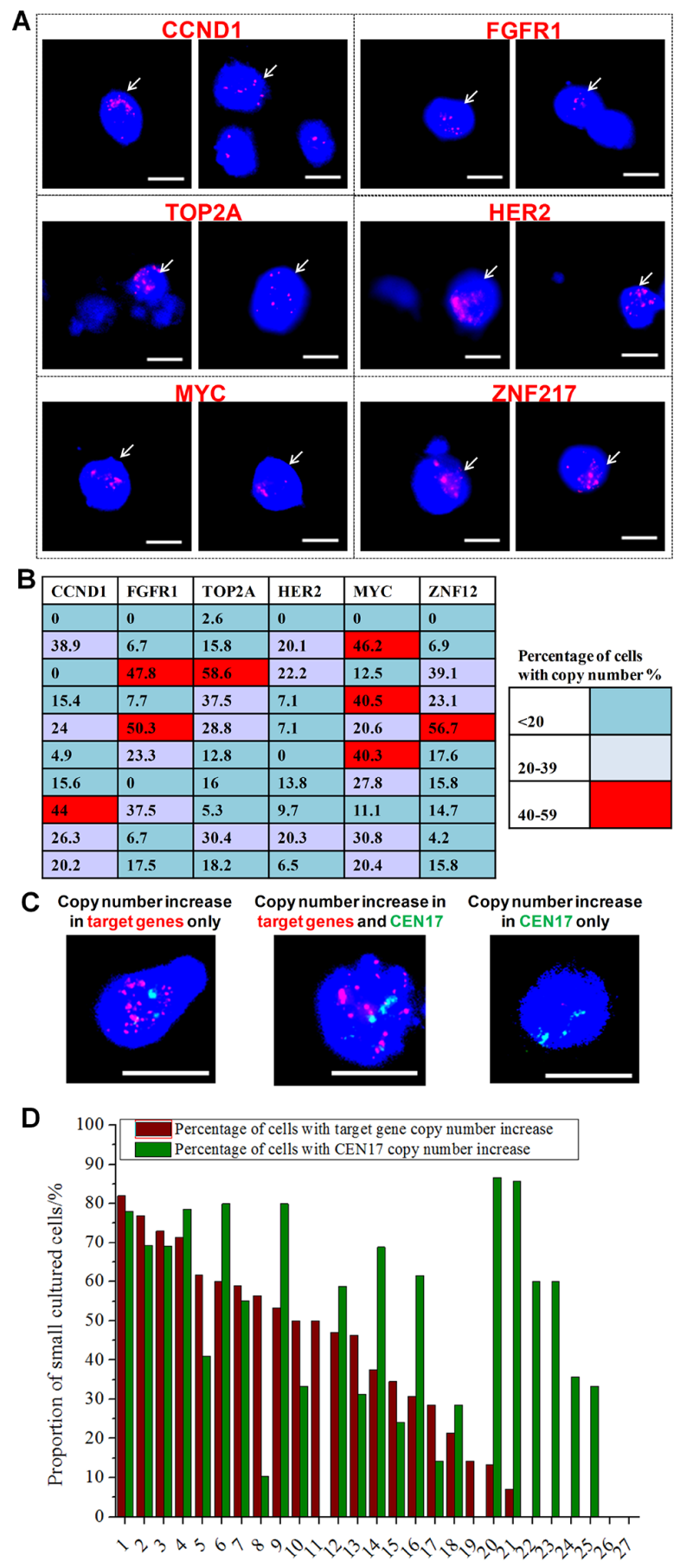

Figure 4: Genomic characterization of cultured CTCs. A. Merged images (bright field, DAPI, spectrum green, spectrum orange) of DNA fluorescence in situ hybridization (FISH)-processed cultured cells processed separately with six target probes (FGFR1, MYC, CCND1, HER2, TOP2A and ZNF217, all red) corresponding to 50\% of breast cancer types. Copy number increase in these genes can be observed in a proportion of the cultured cells ( $\geq 3$ red signals per cell). Scale bar, $20 \mu \mathrm{m}$. B. Heat map representation of the proportion of cells in cultures $(n=10)$ with copy number increase in each of the six genes. $6 / 10$ samples have $40 \%$ or more cells with copy number increase in 1 or more genes. C. Merged images (bright field, DAPI, spectrum green, spectrum orange) of DNA FISH-processed cultured cells using all six target probes (FGFR1, MYC, CCND1, HER2, TOP2A and ZNF217, all red) in each sample, demonstrating copy number increase for target genes in contrast to copy number of centromere for chromosome 17 (CEN17, green). Scale bar, $20 \mu \mathrm{m}$. D. Quantification for the proportion

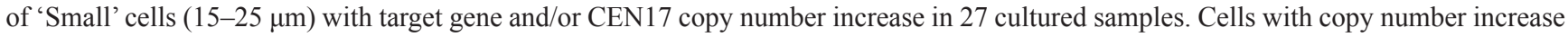
in target genes were determined as those which expressed $\geq 13$ red signals. Cells with copy number increase in CEN17 were determined as those that expressed $\geq 3$ green signals. Numerous samples (21/27) had a proportion of cells with target gene copy number increase, whereas almost all samples (25/27) had a proportion of cells with CEN17 copy number increase. The prevalence of the six target gene copy number increase is detected in $\sim 44 \%$ of all breast cancers. Each bar corresponds to the respective sample as numbered ( $x$-axis). 
To further investigate this correlation between cluster formation and response, serial (4 or more) samples (a total of 90) were collected from 18 patients in Cohort P2A/B over a period of 12-16 weeks; this cohort comprised patients with early-stage breast cancer who had been treated with pre-operative doxorubicin/ cyclophosphamide (AC) with or without Sunitinib as part of a clinical trial (Supplementary Table 1A, Figure 5A) and then undergone breast conserving surgery or mastectomy along with axillary lymph node clearance. We observed a progressive reduction in cluster formation in samples from patients who had undergone increasingly longer treatments. Clusters formed in 30/35 (85.7\%) of pretreatment and post-1-week Sunitinib pre-chemotherapy (post-sutent, pre AC) samples (Figure 5A). More of the post-chemotherapy samples (at least one AC cycle with or without Sunitinib) did not form clusters $(38 / 80 ; 47.5 \%)$ as compared with pre-chemotherapy samples $(5 / 35 ; 14.3 \%)$. All of the negative cultures from post-treatment samples generated cell debris either with or without residual blood cells (Figure 1, Supplementary Table 1A). Interestingly, none of 10 post-surgical samples after 12 weeks of neoadjuvant chemotherapy formed clusters.

To correlate these treatment responses with survival, samples were obtained from 22 patients with refractory metastatic disease (Cohort CTB, Supplementary Table 1B); these patients were enrolled when they presented with progressive disease since their last treatment regimen but before they commenced a new treatment regimen (chemotherapy, endocrine therapy or radiotherapy); blood was collected before and at 3-5 weeks after the new treatment regimen. Post-treatment samples were available from 14/22 patients, and we found an interesting correlation between cluster formation in these samples and clinical response and survival. Cluster formation from post-treatment samples was more common in patients with early radiological progressive disease $(3 / 4$, $75 \%$ ) as compared with those with radiological responsive or stable disease $(4 / 9,44.4 \% ; p=0.308$; Supplementary Table 6). One patient was unassessed at this point in time.
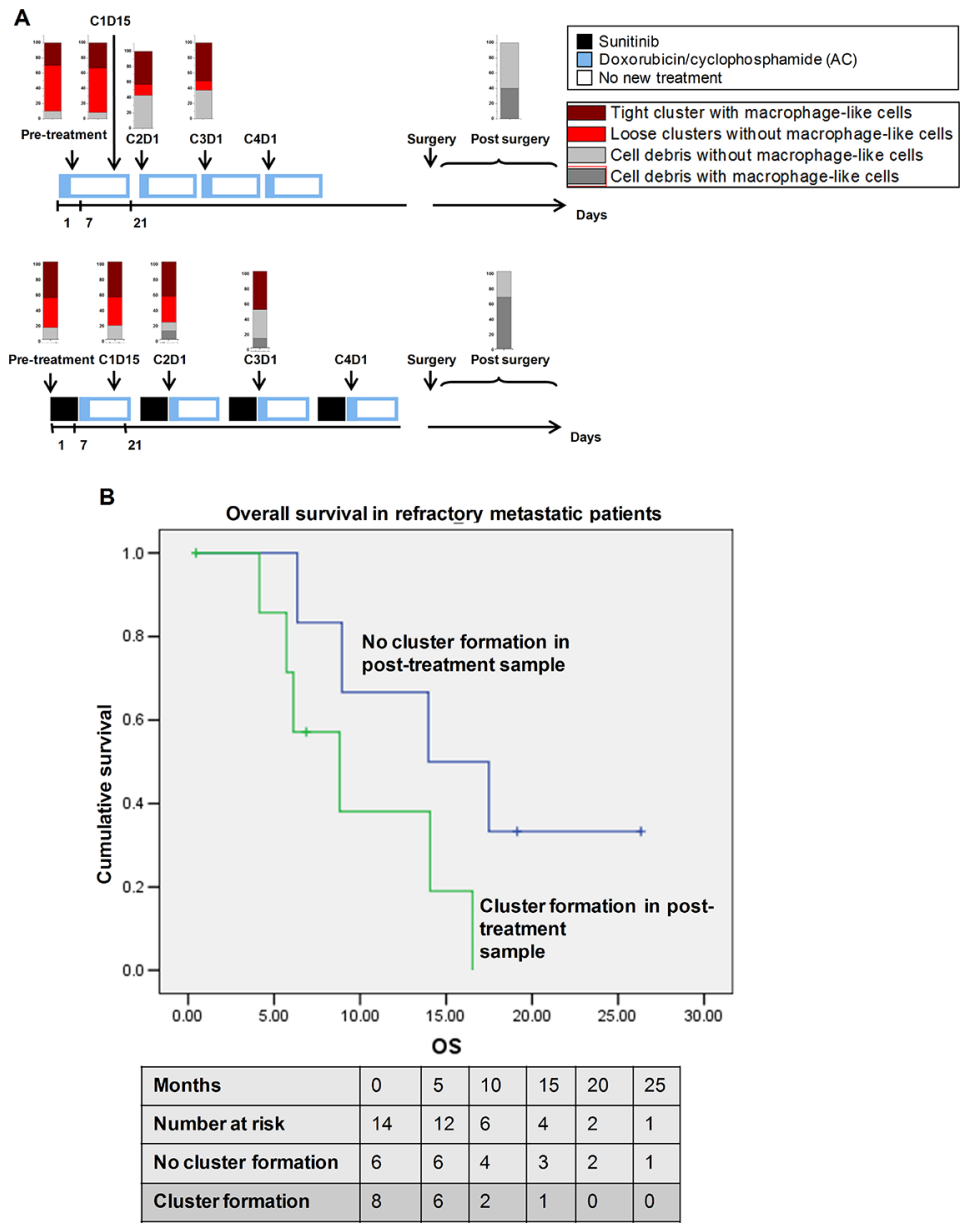

Figure 5: Clinical correlation of cluster formation with patient survival. A. Treatment schedule for the patients $(n=31)$ receiving doxorubicin/cyclophosphamide (AC) with or without Sunitinib. Cluster formation is reduced during therapy cycles, reflecting response to chemotherapy for treatment efficacy. B. Comparison of overall survival in refractory metastatic patients who had or did not have cluster formation in the post-treatment sample $(n=14)$. 
Kaplan-Meier survival analysis showed cluster formation in the post-treatment sample correlated with shorter overall survival, with a mean overall survival of 9.8 months (95\%CI, 5.9-13.7) for patients whose samples generated clusters as compared with a mean overall survival of 16.6 months (95\%CI, 10.4-22.8; log rank $p$-value, 0.087$)$ for patients whose samples did not yield clusters (Figure $5 \mathrm{~B}$ ). Because of the limited sample size, further Cox regression and adjusted analyses were not undertaken. However limited, these findings are intriguing in terms of showing a possible correlation between overall survival and cluster formation, and a larger set of clinical samples is currently being collated to validate these findings.

Finally, we attempted to evaluate the possibility of detecting cultured CTCs in early-stage cancer. The estimated relapse frequency for early-stage breast cancer in Singapore is $10 \%-20 \%$ for stage I, 30\%-40\% for stage II, and $50 \%-70 \%$ for stage III [43]. We analyzed 53 samples from 32 patients with early-stage breast cancer (stages IA-IIIC) who had undergone surgery, had no clinically measurable tumor, and were awaiting, undergoing or had just completed adjuvant chemotherapy (Supplementary Table 1D). Overall, 23/53 (43.4\%) samples formed clusters. Clusters were more commonly observed in patients with pathological involvement of 4 or more lymph nodes $(9 / 16(56 \%))$ as compared with those with 0-3 lymph nodes $(14 / 37(38 \%) ; p=0.214)$. We also correlated cluster formation from cultured CTCs with time since surgery, and found that 10/20 (50\%) samples taken shortly after surgery but before adjuvant chemotherapy formed clusters. For samples taken shortly after completing 3-6 months of adjuvant chemotherapy, cluster formation reduced to just $26 \%(6 / 23)$ but this rebounded to $70 \%(7 / 10)(p=0.049)$ for samples obtained 1 year post-adjuvant chemotherapy. Among these ten samples cluster formation occurred in $2 / 4(50 \%)$ patients with pT1N0M0 disease at later time points, as compared to $5 / 6(83 \%)$ patients with a higher pathological stage of the disease $(p=0.260)$.

\section{DISCUSSION}

Monitoring CTC levels may offer a vast improvement in the current diagnosis of cancer and may help determine the efficacy of selected therapeutic regimes. The copious technical approaches developed for the detection of CTCs [24-27, 37, 44] have thus far failed to retrieve an adequate number of viable cells for culture and characterization, and these methods also require a finicky, delicate or time-consuming procedure to do so. More recent approaches to culture CTCs suffer from low efficiencies $(<20 \%)[12,13,15]$ and the need for preenrichment steps that, paradoxically, result in the loss of CTC counts. Hence, there is still a need for a novel method with improved efficiency and without the need for prior enrichment for practical use in the clinic.
Here, we describe an effective method for the in vitro expansion of CTCs from patients with early stage, locally advanced, or metastatic breast cancers. We observed cell clusters comprising hundreds of cells by Day 14 of culture, comprising both 'Small' $(\leq 25 \mu \mathrm{m})$ and 'Large' $(>25 \mu \mathrm{m})$ cell fractions (Supplementary Figure 2). Most of the Large cells were CD68+ with phagocytic activity and are likely to be macrophages (Supplementary Figure 4). Indeed, macrophage-like cells have been detected in blood samples from various cancer patients by others who have speculated a correlation between the presence of macrophages and the metastasis potential of CTCs [45]. We also detected other CD56+ blood cells that corresponded to NK cells, but could not detect megakaryocytes, monocytes, endothelial cells or MSCs or their lineages derivatives.

The Small cell fraction demonstrated a phenotype that was consistent with the standard definition of CTCs (pan-CK+/CD45-/Hoechst+ with a high N/C ratio [46]). Immunofluorescence labeling revealed that the majority of 'Small' cells were positive for Vimentin and Fascin, and had low levels of EpCAM and E-cadherin, further emphasizing their mesenchymal-like phenotypes (Figure 3). Results from RNA FISH, on the other hand, confirmed the presence of epithelial, epithelial-mesenchymal and fully mesenchymal phenotypes within these cultures, and the varied proportions of these three phenotypes did not appear to be related to the ER/PR/HER2 status of the tumor (Supplementary Figure 13). This heterogeneous expression of both epithelial and mesenchymal markers is consistent with previous reports by others on CTCs in breast [29], prostate $[49,50]$ and head and neck [51] cancers. We further used pooled samples to carry out DNA FISH for six genes previously reported to contribute to driver mutations in breast cancer: MYC, FGFR1, CCND1, HER2, TOP2A, and ZNF217 (Figure 4). Through this assay, we detected locus copy number increase or amplicons in 6/10 (40\%) samples using single probes, and in another 21/27 (77.7\%) samples using combined probes.

Although initial CTC counts may not reflect the potential of a sample to be cultured (due to cancer cell dormancy $[47,48]$ ), it will be worth reviewing the relationship between cluster formation and initial CTC counts among a larger sample cohort. We showed that cultured cells could be transferred to Geltrex ${ }^{\circledR}$ or ultra-low adhesive dishes and grown as spheroids, withstanding multiple passages (Supplementary Figure 12). It is possible that these spheroids could then be maintained and used for ex vivo drug analysis, which has the potential to guide the selection of drugs for therapy. If an ex vivo drug analysis assay is validated and proven to be reliable, then the relatively short turnaround time (14 day culture) is feasible in clinical practice to guide drug selection in the advanced and neoadjuvant, and even in the adjuvant, settings. Future studies will be aimed at establishing correlations between spheroid formation, cancer stage and treatment time-points. 
The maintenance of CTCs in culture after enrichment has been challenging [37]. Most CTC enrichment devices alter cell viability; possibly as a consequence of the lengthy procedures and the loss of potentially clonogenic CTCs. Few techniques have reported the enrichment of viable CTCs $[44,52]$. Affinity-based devices further limit the detection of CTCs to various subpopulations due to the pre-requisite of enriching cells with certain epithelial markers (e.g., EpCAM) [27, 53] that may be downregulated during EMT $[53,54]$. Recent methods for the expansion of CTCs have been reported $[12,15]$, including the initial proof-of-concept study for CTC cultures by Zhang and colleagues [13]. However, these methods are currently still unable to generate cultures efficiently. Emerging inertial microfluidic devices may help to solve this issue $[28,55,56]$.

Our culture system enabled us to perform various characterizations with primary cells after a short-term culture of 14 days. This is more advantageous than using cell lines, since prolonged culture and multiple passages often lead to phenotypes that are no longer representative of the original tumor in terms of the cell's epigenetics and gene expression $[57,58]$. Our method also requires as little as $2.5 \mathrm{ml}$ of blood per $60-\mathrm{mm}$ dish to yield tens of thousands of cells within two weeks, and provides a risk-free approach to CTC harvesting and expansion, with no adverse effects to cell viability, concomitant with the disappearance of WBCs and other non-malignant circulating cells. Our microwell geometry favors the expansion of CTCs by reducing cellsubstrate contact through the use of a non-adhesive plastic substrate. We believe that the curvature of the tapered microwells presents a topography that encourages cell clustering, generating a suitable microenvironmental niche that resembles the tumor microenvironment; this enables CTCs and blood cells to cluster under hypoxic conditions with limited nutrients, as in vivo. Cultures are sheltered within microwells and experience minimal disturbance during media changes, reducing shear stress and cell loss to allow for subsequent expansion. These culture conditions and minimal starting material provide an opportunity for the deep characterization of CTCs, specific to each patient, and a technique with these benefits will be of paramount importance for optimal applications in the clinic, which often require repeated sampling.

The proliferative potential of these cultured cells varies between samples and critically depends on the type and duration of therapy administered to the patients. The absence of cell cluster formation in the microwells from post-treatment samples may reflect treatment efficacy [31], and may possibly reflect a lack of cancer-initiating cells following one or several cycles of treatment. The clusters described here may arise from either single CTCs or microemboli $[28,59]$. Interestingly, we also observed that some of the blood samples that did not initially contain detectable CK+ CTCs were later positive at Day 14 in culture (Supplementary Table 2). This may be a result of the proliferation of very few CTCs with heightened survival characteristics. A previous attempt by Pizon et al. to expand breast epithelial CTCs into spheroids also observed a similar increase in spheroid formation from patients with more aggressive tumors [60], despite variations in the enrichment technique (which selects for epithelial cells under normoxia). Hence, such studies strengthen the hypothesis that CTC cultures may correlate with disease severity.

Our results lend to the hypothesis that systemic therapy affects cluster formation and that a persistence of the ability to cluster may reflect therapy resistance. Cluster formation was seen progressively less frequently in samples with a longer duration since systemic therapy. Strikingly, none of 10 post-surgical samples (after completing neoadjuvant chemotherapy) in the P2A/B cohort demonstrated cluster formation (Supplementary Table 1A). An early loss of cluster formation in this cohort occurred in 1 of 2 patients; this patient achieved pathological complete response after 12 weeks of neoadjuvant chemotherapy. Also, samples from patients with ILC had lower tendencies to form clusters, which could be due to the E-cadherin status of the tumors. However, our sample size of ILC is too small in this study for us to draw firm conclusions about the relationship between ILC, chemotherapy response and CTC cluster formation. Persistent cluster formation in post-treatment samples taken from refractory metastatic disease patients at a time-point 3-5 weeks after treatment (CTB cohort; Supplementary Table 1B)) correlated with early disease progression (within 12 weeks of treatment) and shorter overall survival. We also assessed cluster formation in a small cohort of patients with early-stage breast cancer (CES cohort; Supplementary Table 1D); these patients had undergone surgery and were at sufficient risk clinically to warrant subsequent adjuvant chemotherapy. We were intrigued to find cluster formation in about half of the patients who had no clinically measurable disease, and noted that cluster formation was more frequent in patients with higher lymph node involvement $(\geq 4)$. The positivity rate of 39\% (7/18) for CTC cluster formation in post-surgical specimens from early stage, pathologically node-negative breast cancer patients reported in this study is much higher than the EpCAM-independent CK19 mRNA positivity rate reported in a study involving node-negative breast cancer $(21.6 \%)$ [61]. It will be relevant to investigate more closely the implications of cluster formation in samples from node-negative patients. Interestingly, cluster frequency was reduced from $50 \%$ in immediate post-surgical samples to $26 \%$ in samples taken after 3-6 months of adjuvant chemotherapy. Since we already see a tendency for clusters to form or re-appear in samples from node-positive patients at 1 year after adjuvant chemotherapy, it will be important to ascertain if there is any correlation between adjuvant chemotherapy and the long-term outcomes for patients in a larger cohort (using serial samples). 
The current methods to evaluate response to chemotherapy in the neoadjuvant setting suffer from poor correlation between clinical response and the more relevant endpoint of pathological complete response. A reliable early test to predict pathological complete response is highly desirable and may permit adaptive clinical trials to be conducted in the neoadjuvant setting. The patients recruited in this study are heterogeneous in terms of treatment choice, metastatic sites, and other demographic characteristics. Future studies involving a more homogeneous study population may lead to better understanding of the effects of treatment on cluster formation and the correlation between presence and persistence of clusters with patient survival.

Overall, we established a method for the in vitro expansion of CTCs using a significant number of blood samples $(n=226)$ from patients with early stage, locally advanced or metastatic breast cancers. Blood samples from healthy subjects $(n=16)$ were also cultured in the assay, which consisted of laser-ablated microwells. We investigated the clinical impact of in vitro CTC-clustering as a prognostic and predictive tool for therapy response and explored the phenotypic and genotypic characteristics of the heterogeneous CTCs after 2 weeks in culture. Although we cannot yet confirm the clinical utility (due to small sample cohort and lack of long-term outcomes), this method detects more patients with CTCs than any other method described to date, and can even induce the expansion of CTCs in apparently initially negative samples. We believe that the method is exploitable for the study of drug responses in vitro for locally advanced or metastatic cancer treatment.

\section{MATERIALS AND METHODS}

\section{Preparation of culture assay}

The culture assays were fabricated using uncoated 60-mm petri dishes (Becton Dickinson, Franklin Lakes, NJ) and microwells were patterned using a commercial aircooled 10.6- $\mu \mathrm{m} \mathrm{CO}_{2}$ laser engraving/cutting system at $10 \%$ speed and 50\% power (VLS-2.30, Universal Laser System Inc., Scottsdale, AZ). Typically, each 60-mm patterned dish contains 1350 ellipsoid-shaped tapered wells (Figure 1A). The dimensions of the microwell entrance $(225 \mu \mathrm{m} \times$ $145 \mu \mathrm{m})$ are outlined in Figure 1B and 1D, and the overall structure of the microwell can be demonstrated with a PDMS replica (Figure 1C) (Polydimethylsiloxane) (1:10 ratio (Sylgard 184, Dow Corning, USA)) prepared and demolded, as previously described [27]. Wells were rinsed and incubated with $70 \%$ ethanol for at least 15 min for sterilization.

\section{Sample preparation}

Blood samples were obtained from 92 breast cancer patients (Supplementary Tables 1A-1D). This study was approved by our institutional review board and local ethics committee (DSRB Reference 2012/00105, 2012/00979,
2010/00270, 2010/00691). Blood samples were obtained from patients enrolled into four different studies, including two neoadjuvant studies (doxorubicin/cyclophosphamide with or without Sunitinib [P2A/2B cohort]; paclitaxel/carboplatin/ lapatinib [PCL cohort]), one study of refractory patients treated with various treatment regimens (CTB cohort), and one early-stage breast cancer study after definitive breast cancer surgery (CES cohort). Sixteen healthy volunteers (DSRB-2013/00542) were also recruited to provide control blood samples for validation of culture assay specificity. All patients gave their informed consent for inclusion in this study. Clinicopathological information was recorded for each patient. Samples were collected from each patient once in a single draw, either before or after treatment, or at several timepoints over their treatment period. All blood specimens were collected in sterile EDTA-coated vacutainer tubes (Becton Dickinson) and kept on ice (Figure 1E). The demographic and clinical treatment characteristics for the three cohorts of 60 patients with clinically measurable tumors (i.e., excluding the CES cohort) are summarized in Table 1.

Samples were processed within $10 \mathrm{~h}$ after withdrawal to reduce blood clotting and maintain cell viability. Whole blood was lysed with RBC lysis buffer (Life Technologies, Carlsbad, CA) for 3-5 min with gentle mixing, centrifuged to remove plasma and lysed $\mathrm{RBC}$ fragments, and then washed once with sterile phosphate-buffered saline (PBS). Remnants of the buffer were removed quickly to reduce cell damage upon prolonged exposure. Nucleated cells were re-suspended in fresh, high-glucose Dulbecco's modified Eagle's medium (DMEM) supplemented with 10\% fetal bovine serum (FBS) and 1\% penicillin-streptomycin (all from Invitrogen, Carlsbad, CA). Each processed sample (10 ml of whole blood) was split into four and each $2.5 \mathrm{ml}$ sample seeded into separate $60-\mathrm{mm}$ patterned dishes.

\section{Characterization of clusters in blood cultures}

Samples were kept at $37^{\circ} \mathrm{C}$ in $5 \%(\mathrm{v} / \mathrm{v}) \mathrm{CO}_{2}$ and $1 \% \mathrm{O}_{2}$ under humidified conditions. The culture medium was replaced every $48-72 \mathrm{~h}$ with minimal disturbance to the microwell clusters to avoid cell loss. Clusters were dissociated with pipetting following incubation for a maximum of $3 \mathrm{~min}$ at $37^{\circ} \mathrm{C}$ with $0.01 \%$ trypsin and 5.3 mM EDTA (Lonza, Basel, Switzerland) solution in PBS.

Cultures were maintained for 2-8 weeks, imaged on Days $0,8,14$ and 21 with phase contrast microscopy and analyzed with Image J (NIH, Bethesda, MD). The mean diameters of the structures are the average maximum and minimum dimensions along the same 2D plane of each aggregate.

\section{Cell sorting with spiral inertia microfluidic biochip}

Cultured cells used for histopathological characterization by PAP staining (see below) were sorted for 
Table 1: Patients with clinically measurable tumors

Demographic or clinical characteristics

Age (years)

\begin{tabular}{|l|r|}
\hline Median & 47.5 \\
\hline Range & $33-78$ \\
\hline Race & \\
\hline
\end{tabular}

No. of patients involved $(n=60)$

$\%$

\begin{tabular}{|l|c|r}
\hline Chinese & 38 & 63.3 \\
\hline Indian & 5 & 8.3 \\
\hline Malay & 11 & 18.3 \\
\hline Others & 6 & 10 \\
\hline
\end{tabular}

\section{Histology}

IDC

ILC or IDC with lobular features

\begin{tabular}{c|c}
49 & 81.7 \\
\hline 5 & 8.3 \\
\hline 6 & 10 \\
\hline
\end{tabular}

Others

Tumor grade

\begin{tabular}{|l|l}
\hline 1 &
\end{tabular}

2

3

Not specified

\begin{tabular}{|c|c}
\hline 3 & 5 \\
\hline 18 & 30 \\
\hline 35 & 58.3 \\
\hline 4 & 6.7 \\
\hline
\end{tabular}

Metastatic disease

\begin{tabular}{|l|l|r}
\hline Yes & 25 & 41.7 \\
\hline No & 35 & 58.3 \\
\hline
\end{tabular}

AJCC stage

\begin{tabular}{|c|c|c|}
\hline I & 0 & 0 \\
\hline II & 16 & 26.7 \\
\hline III & 19 & 31.7 \\
\hline IV & 25 & 41.7 \\
\hline \multicolumn{3}{|l|}{ ER status } \\
\hline Negative & 21 & 35 \\
\hline Positive & 39 & 65 \\
\hline \multicolumn{3}{|l|}{ PR status } \\
\hline Negative & 18 & 30 \\
\hline Positive & 42 & 70 \\
\hline \multicolumn{3}{|c|}{ HER2 status } \\
\hline Negative & 47 & 78.3 \\
\hline Positive & 13 & 21.7 \\
\hline
\end{tabular}

(Continued) 
Demographic or clinical characteristics
No. of patients involved $(n=60)$

$\%$

Treatment regimen

\begin{tabular}{|l|c|c|}
\hline $\mathrm{AC}$ & 15 & 25 \\
\hline $\mathrm{AC}+$ Sunitinib & 16 & 26.7 \\
\hline Paclitaxel/carboplatin/lapatinib & 7 & 11.7 \\
\hline Others & 22 & 36.7 \\
\hline
\end{tabular}

IDC = invasive ductal carcinoma; ILC = invasive lobular carcinoma; AJCC, American Joint Committee on Cancer; $\mathrm{ER}=$ estrogen; $\mathrm{PR}=$ progesterone; HER2 = human epidermal growth factor receptor $2 ; \mathrm{AC}=$ doxorubicin/ cyclophosphamide.

better contrast and comparison of morphological differences between populations of different cell sizes. Cells were trypsinized, re-suspended in $1 \mathrm{ml}$ of media within a $10-\mathrm{ml}$ syringe and pumped at $100 \mu \mathrm{l} / \mathrm{min}$ through a PDMS spiral inertia microfluidic biochip [27]. Cells were administered together with the sheath fluid containing PBS at $800 \mu \mathrm{l} / \mathrm{min}$ to obtain size-sorted cell populations for further analysis. Sorted cells were concentrated via centrifugation.

\section{Immunophenotyping of cells}

Cells were fixed with $4 \%$ paraformaldehyde (PFA) (Sigma-Aldrich, St Louis, MO) and permeabilized with $0.1 \%$ Triton X-100 (Thermo Fisher Scientific, San José, CA). Fluorescence microscopy was performed using primary antibodies (Supplementary Table 4) and Dylight 488 or 594 secondary antibodies (Abcam, Cambridge, United Kingdom) and counterstained with Hoechst dye (Invitrogen) (See Supplemental Methods).

\section{Immunophenotyping of cells via cytospots}

CTC cultures or control cell lines (ESCs, MSCs, macrophages, endothelial cells, MCF-7 and MDA-MB-231) were trypsinized, concentrated in PBS, and prepared as cytospots, as described in the Supplemental Methods using a Cytospin 4 cytocentrifuge (Thermo Fisher Scientific). Slides were fixed and permeabilized as above and incubated with a range of primary antibodies (Supplementary Table 4), followed by appropriate Dylight 488 or 594 secondary antibodies (Abcam) and counterstained with Hoechst dye (Invitrogen). Antibody specificity was validated with negative controls using either MCF7, MDA-MB-231 or lysed blood samples at Day 0 before culture. Putative CTCs were identified as $\mathrm{CK}+/ \mathrm{CD} 45-/ H o e c h s t+$ cells.

\section{Enumeration of CTCs}

Ten samples were analyzed to quantify $\mathrm{CK}+$ subpopulations (Figure 2B, Supplementary Table 2). For Day 0 samples, $100 \mu \mathrm{l}$ of freshly lysed samples were fixed onto coated slides using cytospinning (as described above). For
Day 8, 14 and 21 cultures, cells were harvested and fixed onto slides (as described above). Slides were then stained with pan-cytokeratin-FITC, CD45-APC and Hoechst. The entire cytospot was imaged to detect positive cells, and the $\mathrm{CK}+/ \mathrm{CD} 45-/$ Hoechst + cell counts/ml were estimated (Supplementary Table 2).

\section{Histological staining and imaging}

Cytospots were viewed after PAP staining at the Advanced Molecular Pathology Laboratory at IMCB, Singapore. Diff-QUIK Romanowski staining was performed at the Pathology Department of the National University Hospital, Singapore. Imaging was performed with confocal (Olympus Fluoview FV1000, USA) or epifluorescence (Nikon, Japan) microscopy.

\section{DNA and RNA Fluorescence in situ hybridization (FISH)}

Cytospots were fixed with acetic acid/methanol (Sigma-Aldrich) in a 1:3 ratio, added drop-wise to the cell spot at room temperature, and dehydrated through a graded ethanol series $(80 \%, 90 \%$, and $100 \%)$. DNA FISH and RNA FISH were performed as outlined in the Supplemental Methods.

\section{Spheroidogenic assays}

Cultures at Day 14 were harvested, separated into single cells and mixed with Geltrex ${ }^{\circledR}$ (Invitrogen, cat. no. 12760-013) at recommended concentrations in wells of 16-well glass chamber slides (Lab-Tek Products, Miles Laboratories, Naperville, IL). Cultures were maintained under optimal conditions for 1 week, fixed and stained with TRITC-phalloidin (1:1000, Sigma-Aldrich) and Hoechst for $1 \mathrm{~h}$. Chambers were washed and imaged with a confocal microscope to obtain z-stacks of $1 \mu \mathrm{m}$. Alternatively, spheroids were obtained by transferring Day 14 cultured cells to ultra-low adhesive dishes (Cat No; 3473 or 3473; Corning Inc., Corning, NY) and maintained for 10 days in advanced DMEM/F12, reduced-serum 
medium (1:1) (Gibco, Life Technologies, Carlsbad, CA) under normoxia prior to subsequent transfer to amplify the spheroids.

\section{Statistical analysis}

The $\chi^{2}$ test (when the sample size was small) was used to evaluate associations between categorical variables and spheroid formation. A two-way analysis of variance (ANOVA) was employed using Microsoft ${ }^{\mathbb{}}$ Excel $^{\mathbb{}}$ (Redmond, WA) to analyze the flow cytometry data.

\section{ACKNOWLEDGMENTS}

We are grateful to Mr Ting Yuan for technical assistance in assay fabrication. We also appreciate the assistance in technical support and facility usage from personnel at the Mechanobiology Institute (MBI), National University of Singapore (NUS); The Institute of Molecular and Cell Biology (IMCB), an A*STAR (Agency for Science Technology and Research) Institute; and BioSystem and Micromechanics (BioSyM) Department, Singapore-MIT Alliance for Research and Technology (SMART). This work was financially supported by IMCB, A*STAR, and MBI, NUS core funding.

\section{Abbreviations}

CTC, circulating tumor cell; EMT, epithelialmesenchymal transition; N/C nuclear/cytoplasmic ratio; FISH, fluorescence in situ hybridization; CSC, cancer stem cell; ES, embryonic stem; EGFR, epidermal growth factor receptor; CK, cytokeratin; EM, Epithelial-Mesenchymal; E, Epithelial; M, Mesenchymal; NK, natural killer cells; MSC, mesenchymal stem cells; ER, estrogen receptor; PR, progesterone receptor; HER2, human epidermal growth factor receptor 2; PAP, Papanicolaou; AC, doxorubicin/ cyclophosphamide; DMEM, Dulbecco's modified Eagle's medium; FBS, fetal bovine serum; BSA, bovine serum albumin; PBS, phosphate-buffered saline; N, Negative; Y, Positive; C, Chinese; M, Malay; I, Indian; $\mathrm{O}$, Others; IDC, invasive ductal carcinoma; ILC, invasive lobular carcinoma; FAC, 5-fluouracil/doxorubicin/ cyclophosphamide.

\section{Author contributions}

BLK, SCL, PK, CTL and JPT conceived and designed the experiments. BLK and PK performed the experiments. BLK, SCL, TZT, CTL, and JPT analyzed the data. SCL, TZT, MEW, SGO, and SN contributed reagents/materials/analysis tools. BLK, SCL, PK, CTL, and JPT wrote the paper.

\section{COMPETING INTERESTS}

The authors disclose no competing interests.

\section{REFERENCES}

1. Gupta GP, Massague J. Cancer metastasis: building a framework. Cell. 2006; 127:679-695.

2. Pantel K, Alix-Panabieres C, Riethdorf S. Cancer micrometastases. Nat Rev Clin Oncol. 2009; 6:339-351.

3. Husemann Y, Geigl JB, Schubert F, Musiani P, Meyer M, Burghart E, Forni G, Eils R, Fehm T, Riethmuller G, Klein CA. Systemic spread is an early step in breast cancer. Cancer Cell. 2008; 13:58-68.

4. Klein CA. Parallel progression of primary tumours and metastases. Nat Rev Cancer. 2009; 9:302-312.

5. Thiery JP. Epithelial-mesenchymal transitions in tumour progression. Nat Rev Cancer. 2002; 2:442-454.

6. Thiery JP, Lim CT. Tumor dissemination: an EMT affair. Cancer Cell. 2013; 23:272-273.

7. Cristofanilli M, Budd GT, Ellis MJ, Stopeck A, Matera J, Miller MC, Reuben JM, Doyle GV, Allard WJ, Terstappen LW, Hayes DF. Circulating tumor cells, disease progression, and survival in metastatic breast cancer. N Engl J Med. 2004; 351:781-791.

8. Hayes DF, Cristofanilli M, Budd GT, Ellis MJ, Stopeck A, Miller MC, Matera J, Allard WJ, Doyle GV, Terstappen LW. Circulating tumor cells at each followup time point during therapy of metastatic breast cancer patients predict progression-free and overall survival. Clin Cancer Res. 2006; 12:4218-4224.

9. Mocellin S, Keilholz U, Rossi CR, Nitti D. Circulating tumor cells: the 'leukemic phase' of solid cancers. Trends Mol Med. 2006; 12:130-139.

10. Smerage JB, Hayes DF. The measurement and therapeutic implications of circulating tumour cells in breast cancer. $\mathrm{Br}$ J Cancer. 2006; 94:8-12.

11. Yu M, Bardia A, Wittner BS, Stott SL, Smas ME, Ting DT, Isakoff SJ, Ciciliano JC, Wells MN, Shah AM, Concannon KF, Donaldson MC, Sequist LV, Brachtel E, Sgroi D, Baselga J, et al. Circulating breast tumor cells exhibit dynamic changes in epithelial and mesenchymal composition. Science. 2013; 339:580-584.

12. Yu M, Bardia A, Aceto N, Bersani F, Madden MW, Donaldson MC, Desai R, Zhu H, Comaills V, Zheng Z, Wittner BS, Stojanov P, Brachtel E, Sgroi D, Kapur R, Shioda T, et al. Cancer therapy. Ex vivo culture of circulating breast tumor cells for individualized testing of drug susceptibility. Science. 2014; 345:216-220.

13. Zhang L, Ridgway LD, Wetzel MD, Ngo J, Yin W, Kumar D, Goodman JC, Groves MD, Marchetti D. The identification and characterization of breast cancer CTCs competent for brain metastasis. Sci Transl Med. 2013; 5. 180ra148.

14. Cayrefourcq L, Mazard T, Joosse S, Solassol J, Ramos J, Assenat E, Schumacher U, Costes V, Maudelonde T, Pantel K, Alix-Panabieres C. Establishment and characterization of a cell line from human circulating colon cancer cells. Cancer Res. 2015; 75:892-901. 
15. Gao D, Vela I, Sboner A, Iaquinta PJ, Karthaus WR, Gopalan A, Dowling C, Wanjala JN, Undvall EA, Arora VK, Wongvipat J, Kossai M, Ramazanoglu S, Barboza LP, Di W, Cao Z, et al. Organoid cultures derived from patients with advanced prostate cancer. Cell. 2014; 159:176-187.

16. Tosoni D, Di Fiore PP, Pece S. Functional purification of human and mouse mammary stem cells. Methods Mol Biol. 2012; 916:59-79.

17. Al-Hajj M, Wicha MS, Benito-Hernandez A, Morrison SJ, Clarke MF. Prospective identification of tumorigenic breast cancer cells. Proc Natl Acad Sci U S A. 2003; 100:3983-3988.

18. Lindstrom S, Eriksson $M$, Vazin $T$, Sandberg J, Lundeberg J, Frisen J, Andersson-Svahn H. High-density microwell chip for culture and analysis of stem cells. PLoS One. 2009; 4:e6997.

19. Mohr JC, de Pablo JJ, Palecek SP. 3-D microwell culture of human embryonic stem cells. Biomaterials. 2006; 27:6032-6042.

20. Lu X, Kang Y. Hypoxia and hypoxia-inducible factors: master regulators of metastasis. Clin Cancer Res. 2010; 16:5928-5935.

21. Tu, T. Y., Z. Wang, et al. (2014). "Rapid prototyping of concave microwells for the formation of 3D multicellular cancer aggregates for drug screening." Adv Healthc Mater 3(4): 609-616.)

22. Soeda A, Park M, Lee D, Mintz A, AndroutsellisTheotokis A, McKay RD, Engh J, Iwama T, Kunisada T, Kassam AB, Pollack IF, Park DM. Hypoxia promotes expansion of the CD133-positive glioma stem cells through activation of HIF-1alpha. Oncogene. 2009; 28:3949-3959.

23. Bianco P. "Mesenchymal" stem cells. Annu Rev Cell Dev Biol. 2014; 30:677-704.

24. Magbanua MJ, Sosa EV, Scott JH, Simko J, Collins C, Pinkel D, Ryan CJ, Park JW. Isolation and genomic analysis of circulating tumor cells from castration resistant metastatic prostate cancer. BMC Cancer. 2012; 12:78.

25. Stott SL, Hsu CH, Tsukrov DI, Yu M, Miyamoto DT, Waltman BA, Rothenberg SM, Shah AM, Smas ME, Korir GK, Floyd FP Jr, Gilman AJ, Lord JB, Winokur D, Springer S, Irimia D, et al. Isolation of circulating tumor cells using a microvortex-generating herringbone-chip. Proc Natl Acad Sci U S A. 2010; 107:18392-18397.

26. Nagrath S, Sequist LV, Maheswaran S, Bell DW, Irimia D, Ulkus L, Smith MR, Kwak EL, Digumarthy S, Muzikansky A, Ryan P, Balis UJ, Tompkins RG, Haber DA, Toner M. Isolation of rare circulating tumour cells in cancer patients by microchip technology. Nature. 2007; 450:1235-1239.

27. Farace F, Massard C, Vimond N, Drusch F, Jacques N, Billiot F, Laplanche A, Chauchereau A, Lacroix L, Planchard D, Le Moulec S, Andre F, Fizazi K, Soria JC, Vielh P. A direct comparison of CellSearch and ISET for circulating tumour-cell detection in patients with metastatic carcinomas. Br J Cancer. 2011; 105:847-853.

28. Hou HW, Warkiani ME, Khoo BL, Li ZR, Soo RA, Tan DS, Lim WT, Han J, Bhagat AA, Lim CT. Isolation and retrieval of circulating tumor cells using centrifugal forces. Sci Rep. 2013; 3:1259.

29. Kallergi G, Papadaki MA, Politaki E, Mavroudis D, Georgoulias V, Agelaki S. Epithelial to mesenchymal transition markers expressed in circulating tumour cells of early and metastatic breast cancer patients. Breast Cancer Res. 2011; 13:R59.

30. Ho MM, Ng AV, Lam S, Hung JY. Side population in human lung cancer cell lines and tumors is enriched with stem-like cancer cells. Cancer Res. 2007; 67:4827-4833.

31. Li X, Lewis MT, Huang J, Gutierrez C, Osborne CK, Wu MF, Hilsenbeck SG, Pavlick A, Zhang X, Chamness GC, Wong H, Rosen J, Chang JC. Intrinsic resistance of tumorigenic breast cancer cells to chemotherapy. J Natl Cancer Inst. 2008; 100:672-679.

32. Singh A, Settleman J. EMT, cancer stem cells and drug resistance: an emerging axis of evil in the war on cancer. Oncogene. 2010; 29:4741-4751.

33. Eyler CE, Rich JN. Survival of the fittest: cancer stem cells in therapeutic resistance and angiogenesis. J Clin Oncol. 2008; 26:2839-2845.

34. Kang MK, Kang SK. Tumorigenesis of chemotherapeutic drug-resistant cancer stem-like cells in brain glioma. Stem Cells Dev. 2007; 16:837-847.

35. Sharma SV, Lee DY, Li B, Quinlan MP, Takahashi F, Maheswaran S, McDermott U, Azizian N, Zou L, Fischbach MA, Wong KK, Brandstetter K, Wittner B, Ramaswamy S, Classon M, Settleman J. A chromatinmediated reversible drug-tolerant state in cancer cell subpopulations. Cell. 2010; 141:69-80.

36. Mani SA, Guo W, Liao MJ, Eaton EN, Ayyanan A, Zhou AY, Brooks M, Reinhard F, Zhang CC, Shipitsin M, Campbell LL, Polyak K, Brisken C, Yang J, Weinberg RA. The epithelial-mesenchymal transition generates cells with properties of stem cells. Cell. 2008; 133:704-715.

37. Alix-Panabieres C, Vendrell JP, Pelle O, Rebillard X, Riethdorf S, Muller V, Fabbro M, Pantel K. Detection and characterization of putative metastatic precursor cells in cancer patients. Clin Chem. 2007; 53:537-539.

38. Giordano A, Gao H, Anfossi S, Cohen E, Mego M, Lee BN, Tin S, De Laurentiis M, Parker CA, Alvarez RH, Valero V, Ueno NT, De Placido S, Mani SA, Esteva FJ, Cristofanilli M, et al. Epithelial-mesenchymal transition and stem cell markers in patients with HER2-positive metastatic breast cancer. Molecular cancer therapeutics. 2012; 11:2526-2534.

39. Sun YF, Xu Y, Yang XR, Guo W, Zhang X, Qiu SJ, Shi RY, Hu B, Zhou J, Fan J. Circulating stem cell-like epithelial cell adhesion molecule-positive tumor cells indicate poor prognosis of hepatocellular carcinoma after curative resection. Hepatology. 2013; 57:1458-1468.

40. Sieuwerts AM, Kraan J, Bolt J, van der Spoel P, Elstrodt F, Schutte M, Martens JW, Gratama JW, Sleijfer S, Foekens JA. Anti-epithelial cell adhesion molecule antibodies and the detection of circulating normal-like breast tumor cells. J Natl Cancer Inst. 2009; 101:61-66. 
41. Davies H, Bignell GR, Cox C, Stephens P, Edkins S, Clegg S, Teague J, Woffendin H, Garnett MJ, Bottomley W, Davis N, Dicks E, Ewing R, Floyd Y, Gray K, Hall S, et al. Mutations of the BRAF gene in human cancer. Nature. 2002; 417:949-954.

42. Lehmann-Che J, Amira-Bouhidel F, Turpin E, Antoine M, Soliman H, Legres L, Bocquet C, Bernoud R, Flandre E, Varna M, de Roquancourt A, Plassa LF, Giacchetti S, Espie M, de Bazelaire C, Cahen-Doidy L, et al. Immunohistochemical and molecular analyses of HER2 status in breast cancers are highly concordant and complementary approaches. Br J Cancer. 2011; 104:1739-1746.

43. Saxena N, Hartman M, Bhoo-Pathy N, Lim JN, Aw TC, Iau P, Taib NA, Lee SC, Yip CH, Verkooijen HM. Breast cancer in South East Asia: comparison of presentation and outcome between a middle income and a high income country. World journal of surgery. 2012; 36:2838-2846.

44. Khoo BL, Warkiani ME, Tan DS, Bhagat AA, Irwin D, Lau DP, Lim AS, Lim KH, Krisna SS, Lim WT, Yap YS, Lee SC, Soo RA, Han J, Lim CT. Clinical validation of an ultra high-throughput spiral microfluidics for the detection and enrichment of viable circulating tumor cells. PLoS One. 2014; 9:e99409.

45. Adams DL, Martin SS, Alpaugh RK, Charpentier M, Tsai S, Bergan RC, Ogden IM, Catalona W, Chumsri S, Tang CM, Cristofanilli M. Circulating giant macrophages as a potential biomarker of solid tumors. Proc Natl Acad Sci U S A. 2014; 111:3514-3519.

46. Marrinucci D, Bethel K, Lazar D, Fisher J, Huynh E, Clark P, Bruce R, Nieva J, Kuhn P. Cytomorphology of circulating colorectal tumor cells:a small case series. J Oncol. 2010; 2010:861341.

47. Muller V, Stahmann N, Riethdorf S, Rau T, Zabel T, Goetz A, Janicke F, Pantel K. Circulating tumor cells in breast cancer: correlation to bone marrow micrometastases, heterogeneous response to systemic therapy and low proliferative activity. Clin Cancer Res. 2005; 11:3678-3685.

48. Braun S, Kentenich C, Janni W, Hepp F, de Waal J, Willgeroth F, Sommer H, Pantel K. Lack of effect of adjuvant chemotherapy on the elimination of single dormant tumor cells in bone marrow of high-risk breast cancer patients. J Clin Oncol. 2000; 18:80-86.

49. Armstrong AJ, Marengo MS, Oltean S, Kemeny G, Bitting RL, Turnbull JD, Herold CI, Marcom PK, George DJ, Garcia-Blanco MA. Circulating tumor cells from patients with advanced prostate and breast cancer display both epithelial and mesenchymal markers. Mol Cancer Res. 2011; 9:997-1007.

50. Chen CL, Mahalingam D, Osmulski P, Jadhav RR, Wang CM, Leach RJ, Chang TC, Weitman SD, Kumar AP, Sun L, Gaczynska ME, Thompson IM, Huang TH. Singlecell analysis of circulating tumor cells identifies cumulative expression patterns of EMT-related genes in metastatic prostate cancer. Prostate. 2013; 73:813-826.

51. Balasubramanian P, Lang JC, Jatana KR, Miller B, Ozer E, Old M, Schuller DE, Agrawal A, Teknos TN, Summers TA Jr,
Lustberg MB, Zborowski M, Chalmers JJ. Multiparameter analysis, including EMT markers, on negatively enriched blood samples from patients with squamous cell carcinoma of the head and neck. PLoS One. 2012; 7:e42048.

52. Hodgkinson CL, Morrow CJ, Li Y, Metcalf RL, Rothwell DG, Trapani F, Polanski R, Burt DJ, Simpson KL, Morris K, Pepper SD, Nonaka D, Greystoke A, Kelly P, Bola B, Krebs MG, et al. Tumorigenicity and genetic profiling of circulating tumor cells in small-cell lung cancer. Nat Med. 2014; 20:897-903.

53. Pantel K, Brakenhoff RH, Brandt B. Detection, clinical relevance and specific biological properties of disseminating tumour cells. Nat Rev Cancer. 2008; 8:329-340.

54. Spizzo G, Went P, Dirnhofer S, Obrist P, Simon R, Spichtin H, Maurer R, Metzger U, von Castelberg B, Bart R, Stopatschinskaya S, Kochli OR, Haas P, Mross F, Zuber M, Dietrich H, et al. High Ep-CAM expression is associated with poor prognosis in node-positive breast cancer. Breast Cancer Res Treat. 2004; 86:207-213.

55. Warkiani ME, Khoo BL, Tan DS, Bhagat AA, Lim WT, Yap YS, Lee SC, Soo RA, Han J, Lim CT. An ultrahigh-throughput spiral microfluidic biochip for the enrichment of circulating tumor cells. Analyst. 2014; 139:3245-3255.

56. Warkiani ME, Guan G, Luan KB, Lee WC, Bhagat AA, Chaudhuri PK, Tan DS, Lim WT, Lee SC, Chen PC, Lim CT, Han J. Slanted spiral microfluidics for the ultrafast, label-free isolation of circulating tumor cells. Lab Chip. 2014; 14:128-137.

57. Lacroix M, Leclercq G. Relevance of breast cancer cell lines as models for breast tumours: an update. Breast Cancer Res Treat. 2004; 83:249-289.

58. van Staveren WC, Solis DY, Hebrant A, Detours V, Dumont JE, Maenhaut C. Human cancer cell lines: Experimental models for cancer cells in situ? For cancer stem cells? Biochim Biophys Acta. 2009; 2:92-103.

59. Aceto N, Bardia A, Miyamoto DT, Donaldson MC, Wittner BS, Spencer JA, Yu M, Pely A, Engstrom A, Zhu H, Brannigan BW, Kapur R, Stott SL, Shioda T, Ramaswamy S, Ting DT, et al. Circulating tumor cell clusters are oligoclonal precursors of breast cancer metastasis. Cell. 2014; 158:1110-1122.

60. Pizon M, Zimon D, Carl S, Pachmann U, Pachmann K, Camara O. Heterogeneity of circulating epithelial tumour cells from individual patients with respect to expression profiles and clonal growth (sphere formation) in breast cancer. Ecancermedicalscience. 2013; 7:343.

61. Xenidis N, Perraki M, Kafousi M, Apostolaki S, Bolonaki I, Stathopoulou A, Kalbakis K, Androulakis N, Kouroussis C, Pallis T, Christophylakis C, Argyraki K, Lianidou ES, Stathopoulos S, Georgoulias V, Mavroudis D. Predictive and prognostic value of peripheral blood cytokeratin-19 mRNA-positive cells detected by real-time polymerase chain reaction in node-negative breast cancer patients. J Clin Oncol. 2006; 24:3756-3762. 